Male Populus cathayana than female shows higher photosynthesis and less cellular injury through ABA-induced manganese transporting inhibition under high manganese condition

Chen, Fugui

2018-02

Chen , F , Shen , J , Min , D , Ke , L , Tian , X, Korpelainen, H \& Li , C 2018 , ' Male Populus cathayana than female shows higher photosynthesis and less cellular injury through ABA-induced manganese transporting inhibition under high manganese condition ' , Trees : Structure and Function , vol. 32 , no. 1 , pp. 255-263 . https://doi.org/10.1007/s00468-017-1628-1

http://hdl.handle.net/10138/307673

https://doi.org/10.1007/s00468-017-1628-1

cc_by_nc_sa

acceptedVersion

Downloaded from Helda, University of Helsinki institutional repository.

This is an electronic reprint of the original article.

This reprint may differ from the original in pagination and typographic detail.

Please cite the original version. 


\title{
Male Populus cathayana than female shows higher photosynthesis and less cellular injury through ABA-induced manganese transporting inhibition under high manganese condition
}

\author{
Fugui Chen ${ }^{1} \cdot J_{u a n} \mathrm{Shen}^{1} \cdot \operatorname{Dou} \mathrm{Min}^{1} \cdot \mathrm{Lixia}_{\mathrm{Ke}^{2}} \cdot \mathrm{Xin}_{\mathrm{Tian}^{4}} \cdot$ Helena Korpelainen $^{5} \cdot$ \\ Chunyang $\mathbf{L i}^{3}$
}

Received: 27 July 2017 / Accepted: 11 October 2017

(c) Springer-Verlag GmbH Germany 2017

\begin{abstract}
Key message High Mn poisoned male and female $\mathrm{Popu}$ lus cathayana. The toxicity could be alleviated by exogenous ABA application. Intriguingly, ABA granted higher resistance to males than to females under high Mn stress because ABA could induce more blocking of Mn translocation to leaf in males than in females.

Abstract Abscisic acid (ABA) is involved in plants' adaptive responses to various environmental stresses. However, little is known about the sex-related detoxification of ABA in plants under excess manganese $(\mathrm{Mn})$ conditions. To reveal potentially different ABA detoxification mechanisms between Populus cathayana males and females against excess $\mathrm{Mn}$ exposure, photosynthesis performance, $\mathrm{Mn}^{2+}$ concentrations and morphologic changes were investigated.
\end{abstract}

Communicated by S. Chen.

Chunyang Li

licy@hznu.edu.cn

1 The Research Center of Life Omics and Health and Anhui Provincial Key Laboratory of the Conservation and Exploitation of Biological Resources, College of Life Sciences, Anhui Normal University, Wuhu 241000, Anhui, China

2 Key Laboratory of Biotic Environment and Ecological Safety in Anhui Province, College of Life Sciences, Anhui Normal University, Wuhu 241000, Anhui, China

3 College of Life and Environmental Sciences, Hangzhou Normal University, Hangzhou 310036, China

4 Department of Biological Sciences and NUS Centre for BioImaging Sciences, National University of Singapore, Singapore 117543, Singapore

5 Department of Agricultural Sciences, Viikki Plant Science Centre, University of Helsinki, P.O. Box 27, 00014 Helsinki, Finland
High Mn stress led to a more severe chloroplast destruction and, thus, greater reduction in the photosynthesis of $P$. cathayana females when compared to males. Under high Mn conditions, Mn reallocated mainly to leaves in females, while in males, it was distributed equally to roots and leaves. With the application of ABA, photosynthesis was restored more in males and more integrated grana in males than in females. It should be noted that Mn concentrations in males were lower in leaves and higher in roots and stems than those in females when treated with the combination of $\mathrm{Mn}$ and ABA. Conclusively, due to the reduction of root-shoot $\mathrm{Mn}$ transportation induced by ABA in $P$. cathayana males, males experienced less physiological injuries than do females, which suggest that males possess greater ABA-inducible resistance to Mn stress than do females.

Keywords Abscisic acid $\cdot$ Mn toxicity $\cdot$ Dioecy $\cdot$ Poplar Sexual differences

\section{Introduction}

Manganese (Mn) is an essential element for plant growth and development. It is needed during photosynthesis and it functions in the decomposition of superoxide (Chen et al. 2013c; Millaleo et al. 2010; Pittman 2005). However, in acidic soils and mine spoils, the presence of excessive $\mathrm{Mn}$ leads to serious heavy metal toxicity for plants (Foy et al. 1978; Reis and Junior 2011). Previous studies believed that once excessive $\mathrm{Mn}$ is transported to the shoot, especially to leaves, the photosynthetic apparatus will be harmed and the gas-exchange process will be disturbed (Doncheva et al. 2005; Lidon et al. 2004; Reis and Junior 2011). Afterwards, necrotic and brown spots will emerge in leaves (Rezai and Farboodnia 2008). Yet, to counteract Mn stress, plants have 
evolved sophisticated mechanisms to cope with high Mn stress, such as blocking off Mn transportation from roots to leaves (Dorling et al. 2011; Fernando et al. 2008; Xue et al. 2004). It has been demonstrated that blocking off Mn transportation is related to the presence of the endogenous stress-related phytohormone, ABA (De Vleesschauwer et al. 2010; Raghavendra et al. 2010).

ABA is indispensible in plants' abiotic and biotic stress resistances (Peleg and Blumwald 2011; Pieterse et al. 2012; Ryu et al. 2010; Wang et al. 2011; Xu et al. 2011). During heavy metal detoxification, ABA can protect plants through the inhibition of the transportation of toxic heavy metal from root to aerial parts. Previous study has found that cadmium uptake was inhibited by exogenous ABA application in Arabidopsis (Fan et al. 2014). Among woody plants, exogenous ABA alleviates zinc uptake and accumulation in Populus $\times$ canescens under excess zinc conditions (Shi et al. 2015). In different cadmium resistant cultivars of rice, exogenous ABA decreases the cadmium content, and enhances the cadmium tolerance of cadmium-sensitive cultivars (Hsu and Kao 2003). However, whether ABA functions differently in $\mathrm{Mn}$ resistance between different sexes is still unclear.

Females and males of dioecious plants show different tolerances to environmental stresses, which is largely due to their different investments to reproduction (Barrett and Hough 2012; Case and Barrett 2004; Freeman et al. 1976; Wallace and Rundel 1979). Since females allocate more nutrients and energy into reproduction than to stress resistance, they are generally more susceptible to adverse environmental stresses than males (Chen et al. 2015; Obeso 2002; Stark et al. 2000). Nevertheless, few studies have reported differences between females and males in the perception of a stress signal (Barrett and Hough 2012; Chen et al. 2010; Crossgrove and Zheng 2004; De Vleesschauwer et al. 2010; Hultine et al. 2013; Lee et al. 2004; Wallace and Rundel 1979). In our study, the following hypotheses were tested: (1) the toxicity could be alleviated by an exogenous ABA application; (2) ABA could grant greater resistance to males than to females under high Mn stress by blocking off Mn translocation to leaves more effectively in males than in females. We aim to uncover whether ABA, the stressrelated signal, functions differently in $P$. cathayana males and females under high Mn conditions.

\section{Materials and methods}

\section{Plant materials and experimental design}

Cuttings of $P$. cathayana males and females were selected among $F_{1}$ individuals, which were derived from a controlled intraspecific cross between two $P$. cathayana genotypes selected from their natural habitat (Ledu, $36^{\circ} 31^{\prime} \mathrm{N}$, $102^{\circ} 28^{\prime} \mathrm{E}, 3160 \mathrm{~m}$ alt.) in the Qinghai Province, China. Of each sex, 45 healthy and uniform cuttings germinated from 2-year old rootstocks were selected and grown in a naturally lit, well-ventilated greenhouse (average temperature and relative humidity being $27{ }^{\circ} \mathrm{C}$ and $70 \%$, respectively) for 4 weeks. Each cutting grew in a 10-L plastic pot filled with $8 \mathrm{~kg}$ nursery soil and $8 \mathrm{~g}$ slow-release fertilizer $(13 \%$ $\mathrm{N}, 10 \% \mathrm{P}$ and $14 \% \mathrm{~K}$ ). When cuttings reached about $50 \mathrm{~cm}$ in height, they were treated with ABA and high Mn stress. In Mn stress experiments, cuttings were irrigated with $1 \mathrm{~L}$ deionized water containing $2 \mathrm{mM} \mathrm{MnCl} \mathrm{M}_{2}$ every day during the treatment according to our previous studies with changes (Lei et al. 2007). In the ABA experiment, leaves of cuttings were daily sprayed evenly with $10 \mathrm{~mL} 50 \mu \mathrm{M}$ ABA in $0.5 \%$ (v/v) Tween 20 (Yin et al. 2004). In the combined Mn and ABA experiment, plants were sprayed simultaneously with $10 \mathrm{~mL} 50 \mu \mathrm{MABA}$ in $0.5 \%$ (v/v) Tween 20 and irrigated with $1 \mathrm{~L} 2 \mathrm{mM} \mathrm{MnCl}_{2}$. In control experiments, cuttings were sprayed and irrigated with equal volumes of deionized water and $0.5 \%(\mathrm{v} / \mathrm{v})$ Tween 20 . The treatments lasted 4 weeks.

\section{Gas-exchange assay}

Gas-exchange was measured at the end of ABA and Mn treatments, from 08:00 to 11:30 h with the Li-6400 portable photosynthesis measuring system (Li-Cor Inc., Lincoln, NE, USA) on the fourth or fifth fully expanded leaf of each sample. The measuring conditions were as follows: leaf temperature $27^{\circ} \mathrm{C}$, leaf-air vapor pressure deficit $1.5 \pm 0.5 \mathrm{kPa}$, photosynthetic photon flux $1400 \mu \mathrm{mol} \mathrm{m} \mathrm{m}^{-2} \mathrm{~s}^{-1}$, relative air humidity $70 \%$, and ambient $\mathrm{CO}_{2}$ concentration $390 \pm 8 \mu \mathrm{mol} \mathrm{mol}^{-1}$. Chlorophyll fluorescence of the sameyear leaves was measured with the PAM chlorophyll fluorometer (PAM 2100, Walz, Effeltrich, Germany). ETR and $\Phi$ were calculated (Baker 2008).

\section{Ultrastructural observations of mesophyll cells}

For ultrastructural observations, about $1 \times 2 \mathrm{~cm}$ fresh leaf segments without major veins were cut from the fourth or fifth fully expanded leaf. Leaf segments were fixed in 3\% glutaraldehyde (in $0.2 \mathrm{M}$ sodium phosphate buffer, $\mathrm{pH}$ 7.2) for $6-8 \mathrm{~h}$, post fixed in $2 \%$ osmium tetraoxide for $2 \mathrm{~h}$ and dehydrated in ethanol with concentrations increasing by $10 \%$ from 50 to $100 \%$, followed by acetone. Leaf segments were then embedded in epon-araldite. Ultra-thin sections $(80 \mathrm{~nm})$ were sliced, mounted and counterstained with $3 \%$ $(\mathrm{w} / \mathrm{v})$ uranyl acetate in ethanol and lead citrate. Images were collected by a transmission electron microscope (H-600IV, Hitachi Co., Japan) at an accelerating voltage of $60.0 \mathrm{kV}$ (Chen et al. 2010). 


\section{$\mathrm{Mn}^{2+}$ content analysis}

To detect the Mn concentration, roots, stems and leaves of $P$. cathayana males and females were segmented and cleaned with water. After that, the samples were soaked in $0.2 \%$ EDTA for $2 \mathrm{~h}$ and then rinsed thoroughly with deionized water to eliminate possible chemical contamination. Afterwards, they were dried at $80{ }^{\circ} \mathrm{C}(48 \mathrm{~h})$ and weighed. The dried samples were digested in a mixture of $\mathrm{HNO}_{3} / \mathrm{HClO}_{4}$ (4:1), and the Mn concentration was determined using an inductively coupled argon plasma emission spectrometry (Model 1CAP 61E; Thermo-Jarrell Ash, Waltham, MA, USA) (Chen et al. 2013a). The $\mathrm{Mn}^{2+}$ ratio were calculated by dividing the average $\mathrm{Mn}^{2+}$ concentration of different tissues to average whole $\mathrm{Mn}^{2+}$ concentration of each sex and treatment separately.

\section{Statistical analysis}

All data were analyzed with the software Statistical Package for the Social Sciences (SPSS) version 19.0. Three-way analyses of variance (ANOVAs) were employed to test the overall effects of sex, Mn and ABA on physiological and biochemical parameters. Before ANOVAs, data were checked for normality and the homogeneity of variances. For Mn concentrations in roots, stems and leaves, which showed heterogeneous variances, the data were ln-transformed to obtain a normal distribution and homogeneity of variances.
Post hoc comparisons were conducted using the Duncan test at a significance level of $P \leq 0.05$.

To determine whether high $\mathrm{Mn}$ and exogenous ABA affect Mn concentrations of $P$. cathayana males and females, we organized the data into three traits $\times 2$ sexes under three treatments matrix. To find out whether female responses to $\mathrm{Mn}$ and ABA were similar to those of males, we compared Mn concentrations using a principal component analysis (PCA). For PCA, three biological replicate data of $\mathrm{Mn}^{2+}$ concentrations in root, stem and leaf were standardized and subsequently computed by SIMCA version 13.0 (http:// umetrics.com/products/simca).

\section{Results}

\section{Photosynthetic changes}

To determine the effects of high Mn and ABA spraying on gas-exchange in $P$. cathayana males and females, we measured the net photosynthesis rate $(A)$, stomatal conductance $\left(g_{\mathrm{s}}\right)$ and transpiration rate $(E)$. Table 1 shows that the exposure to high Mn led to significant decreases of $A, g_{\text {s }}$ and $E$ in both male and female seedlings. However, the effects of ABA spraying alone did not dramatically change the net photosynthesis rate in either sex. It should be noted that $A$, $g_{\mathrm{s}}$ and $E$ decreased more in females than in males when grown under high Mn compared to control condition. When
Table 1 Net photosynthesis rate $(A)$, stomatal conductance $\left(g_{\mathrm{s}}\right)$ and transpiration rate $(E)$ in $P$. cathayana males and females, as affected by manganese, ABA and their combination

\begin{tabular}{lcllll}
\hline $\mathrm{MnCl}_{2}(\mathrm{mM})$ & $\begin{array}{c}\mathrm{ABA} \\
(\mu \mathrm{M})\end{array}$ & Sex & $A\left(\mu \mathrm{mol} \mathrm{m}^{-2} \mathrm{~s}^{-1}\right)$ & $g_{\mathrm{s}}\left(\mathrm{mol} \mathrm{m}^{-2} \mathrm{~s}^{-1}\right)$ & $E\left(\mathrm{mmol} \mathrm{m}^{-2} \mathrm{~s}^{-1}\right)$ \\
\hline 0 & 0 & Male & $20.462 \pm 0.365 \mathrm{ab}$ & $0.542 \pm 0.092 \mathrm{a}$ & $9.822 \pm 0.813 \mathrm{a}$ \\
0 & 50 & Male & $23.035 \pm 0.239 \mathrm{a}$ & $0.521 \pm 0.030 \mathrm{a}$ & $9.488 \pm 0.239 \mathrm{a}$ \\
2.0 & 0 & Male & $6.901 \pm 0.265 \mathrm{c}$ & $0.027 \pm 0.004 \mathrm{c}$ & $0.913 \pm 0.109 \mathrm{c}$ \\
2.0 & 50 & Male & $9.016 \pm 1.522 \mathrm{c}$ & $0.042 \pm 0.014 \mathrm{c}$ & $1.311 \pm 0.401 \mathrm{c}$ \\
0 & 0 & Female & $17.235 \pm 0.778 \mathrm{~b}$ & $0.588 \pm 0.016 \mathrm{a}$ & $11.121 \pm 0.247 \mathrm{a}$ \\
0 & 50 & Female & $17.989 \pm 1.031 \mathrm{~b}$ & $0.255 \pm 0.063 \mathrm{~b}$ & $6.000 \pm 1.017 \mathrm{~b}$ \\
2.0 & 0 & Female & $3.112 \pm 0.557 \mathrm{~d}$ & $0.011 \pm 0.001 \mathrm{c}$ & $0.388 \pm 0.095 \mathrm{c}$ \\
2.0 & 50 & Female & $7.949 \pm 2.540 \mathrm{c}$ & $0.040 \pm 0.022 \mathrm{c}$ & $1.305 \pm 0.652 \mathrm{c}$ \\
& & $F_{\mathrm{s}}$ & $* * *$ & $\mathrm{NS}$ & $\mathrm{NS}$ \\
& & $F_{\mathrm{Mn}}$ & $* * *$ & $* * *$ & $* * *$ \\
& $F_{\mathrm{ABA}}$ & $* *$ & $*$ & $*$ \\
& $F_{\mathrm{s} \times \mathrm{Mn}}$ & $\mathrm{NS}$ & $\mathrm{NS}$ & $*$ \\
& $F_{\mathrm{s} \times \mathrm{ABA}}$ & $\mathrm{NS}$ & $*$ & $* *$ \\
& $F_{\mathrm{Mn} \times \mathrm{ABA}}$ & $\mathrm{NS}$ & $* *$ & $*$ \\
& $F_{\mathrm{s} \times \mathrm{Mn} \times \mathrm{ABA}}$ & $\mathrm{NS}$ & $*$ & $*$ \\
\hline
\end{tabular}

Each value is the mean $\pm \mathrm{SE}(n=3)$

$F_{s}$ sex effect, $F_{M n}$ manganese treatment effect, $F_{A B A}$ ABA treatment effect, $F_{s \times M n}$ the interactive effect of sex and manganese, $F_{s \times A B A}$ the interactive effect of sex and ABA, $F_{M n \times A B A}$ the interactive effect of manganese and ABA, $F_{s \times M n \times A B A}$ the interactive effect of sex, manganese and ABA, $N S$ not significant, $P>0.05 ; *$, $0.01<P \leq 0.05 ; * *, 0.001<P \leq 0.01$; and $* * *, P \leq 0.001$. Different letters represent statistical significance between treatments at $P<0.05$ according to Duncan multiple range tests 
sprayed with $\mathrm{ABA}$ at the same time, $A$ in males was greater than that in females. To examine the possible role of ABA in photosynthetic responses to high $\mathrm{Mn}$ stress, chlorophyll fluorescence parameters, which are indicators of photosynthetic capacity, were measured. When treated with $\mathrm{Mn}$ alone, $F_{\mathrm{m}}$ (maximum fluorescence), $F_{\mathrm{v}} / F_{\mathrm{m}}$ (ratio of variable to maximum fluorescence - the quantum efficiency of open photosystem II centers), ETR (photosynthetic electron transport rate), and $\Phi$ (effective quantum yield of photosystem II) decreased in male and female leaves (Table 2). By contrast, $F_{\mathrm{m}}, F_{\mathrm{v}} / F_{\mathrm{m}}$, ETR and $\Phi$ increased in both females and males when treated with the combination of $\mathrm{Mn}$ and ABA compared to the Mn treatment alone. The results indicated that stress caused by high $\mathrm{Mn}$ reduced photosynthetic performance in both $P$. cathayana males and females, while ABA spraying could relieve the stress effect.

\section{Differences in Mn location}

Mn contents in male and female leaves, stems, and roots were assayed. Mn alone and the combined treatment of Mn and ABA led to a significant increase in the Mn contents of leaves in both sexes. However, there were no differences between control and ABA-treated seedlings (Fig. 1a). In stems, the Mn treatment alone and $\mathrm{Mn} \times \mathrm{ABA}$ treatment reduced Mn contents (Fig. 1b), and in roots, $\mathrm{Mn} \times \mathrm{ABA}$ led to a greater reduction of $\mathrm{Mn}$ contents in females than in males (Fig. 1c). It should be noted that the Mn concentration in female leaves when sprayed with ABA under high Mn conditions was significantly higher than that in males but lower in stems and roots (Fig. 1a-c). Concerning the Mn distribution in leaves, stems and roots, females and males showed dramatic differences (Fig. 1d). In control females, 58.3 and $41.7 \%$ of Mn was distributed in roots and above-ground parts, respectively, but only $1.9 \%$ in leaves. While in control males, most Mn (85.8\%) was in stems and only $8.7 \%$ in roots (Fig. 1d), indicating that under optimal conditions, most Mn accumulated in aboveground parts in males, while in females it was distributed evenly in above- and below-ground parts. When facing with high $\mathrm{Mn}$, the proportion of $\mathrm{Mn}$ increased to $92.7 \%$ in female leaves, while only $6.9 \%$ remained in roots. On the contrary, in males, the proportion of $\mathrm{Mn}$ in leaves and roots increased from 5.5 to $47.7 \%$ and from 8.7 to $51.6 \%$, respectively. These data indicate that Mn stress could induce the root-oriented relocation in males and aerialsoriented relocation in females of $\mathrm{Mn}^{2+}$. Furthermore, ABA spraying induced most $\mathrm{Mn}$, about $95.5 \%$ of all $\mathrm{Mn}$, to concentrate in male roots when exposed to high $\mathrm{Mn}$. On the contrary, Mn concentrations were the same in Mn-treated female leaves whether treated with or without ABA. Our result indicated that ABA might block off Mn transportation from roots to leaves in males but not in females.
Table 2 The maximum fluorescence $\left(F_{\mathrm{m}}\right)$, the ratio of variable to maximum fluorescence $\left(F_{\mathrm{v}} / F_{\mathrm{m}}\right)$, the apparent photosynthetic electron transport rate (ETR) and the effective quantum yield of photosystem
II $(\Phi)$ in $P$. cathayana males and females, as affected by manganese, $\mathrm{ABA}$ and their combination

\begin{tabular}{|c|c|c|c|c|c|c|}
\hline $\mathrm{MnCl}_{2}(\mathrm{mM})$ & $\mathrm{ABA}(\mu \mathrm{M})$ & Sex & $F_{\mathrm{m}}$ & $F_{\mathrm{v}} / F_{\mathrm{m}}$ & ETR & $\Phi$ \\
\hline 0 & 0 & Male & $1.423 \pm 0.041 \mathrm{a}$ & $0.808 \pm 0.003 \mathrm{a}$ & $93.167 \pm 1.692 \mathrm{a}$ & $0.740 \pm 0.013 \mathrm{a}$ \\
\hline 0 & 50 & Male & $1.417 \pm 0.051 \mathrm{a}$ & $0.802 \pm 0.008 \mathrm{a}$ & $92.900 \pm 0.656 \mathrm{a}$ & $0.737 \pm 0.005 \mathrm{a}$ \\
\hline 2.0 & 0 & Male & $1.181 \pm 0.103 b$ & $0.752 \pm 0.009 \mathrm{~b}$ & $88.500 \pm 0.436 \mathrm{bc}$ & $0.703 \pm 0.004 \mathrm{bc}$ \\
\hline 2.0 & 50 & Male & $1.287 \pm 0.069 \mathrm{ab}$ & $0.789 \pm 0.011 \mathrm{a}$ & $90.633 \pm 1.450 \mathrm{ab}$ & $0.719 \pm 0.011 \mathrm{ab}$ \\
\hline 0 & 0 & Female & $1.423 \pm 0.051 \mathrm{a}$ & $0.806 \pm 0.010 \mathrm{a}$ & $91.833 \pm 1.677 \mathrm{ab}$ & $0.729 \pm 0.013 \mathrm{ab}$ \\
\hline 0 & 50 & Female & $1.295 \pm 0.131 \mathrm{ab}$ & $0.797 \pm 0.010 \mathrm{a}$ & $91.067 \pm 1.474 \mathrm{ab}$ & $0.723 \pm 0.012 \mathrm{ab}$ \\
\hline 2.0 & 0 & Female & $1.268 \pm 0.032 b$ & $0.766 \pm 0.022 b$ & $87.167 \pm 3.855 \mathrm{c}$ & $0.692 \pm 0.030 \mathrm{c}$ \\
\hline \multirow[t]{8}{*}{2.0} & 50 & Female & $1.295 \pm 0.050 \mathrm{ab}$ & $0.792 \pm 0.007 \mathrm{a}$ & $90.767 \pm 0.289 a b$ & $0.720 \pm 0.002 \mathrm{ab}$ \\
\hline & & $F_{\mathrm{s}}$ & NS & NS & NS & NS \\
\hline & & $F_{\mathrm{Mn}}$ & $* * *$ & $* * *$ & $* * *$ & $* * *$ \\
\hline & & $F_{\mathrm{ABA}}$ & NS & $*$ & NS & NS \\
\hline & & $F_{\mathrm{s} \times \mathrm{Mn}}$ & NS & NS & NS & NS \\
\hline & & $F_{\mathrm{s} \times \mathrm{ABA}}$ & NS & NS & NS & NS \\
\hline & & $F_{\mathrm{Mn} \times \mathrm{ABA}}$ & $*$ & $* * *$ & $*$ & $*$ \\
\hline & & $F_{\mathrm{s} \times \mathrm{Mn} \times \mathrm{ABA}}$ & NS & NS & NS & NS \\
\hline
\end{tabular}

Each value is the mean $\pm \operatorname{SE}(n=3)$

$F_{s}$ sex effect, $F_{M n}$ manganese treatment effect, $F_{A B A}$ ABA treatment effect, $F_{s \times M n}$ the interactive effect of sex and manganese, $F_{s \times A B A}$ the interactive effect of sex and ABA, $F_{M n \times A B A}$ the interactive effect of manganese and ABA, $F_{s \times M n \times A B A}$ the interactive effect of sex, manganese and ABA, NS not significant, $P>0.05 ; *, 0.01<P \leq 0.05$; **, $0.001<P \leq 0.01$; and $* * *, P \leq 0.001$. Different letters represent statistical significance between treatments at $P<0.05$ according to Duncan multiple range tests 

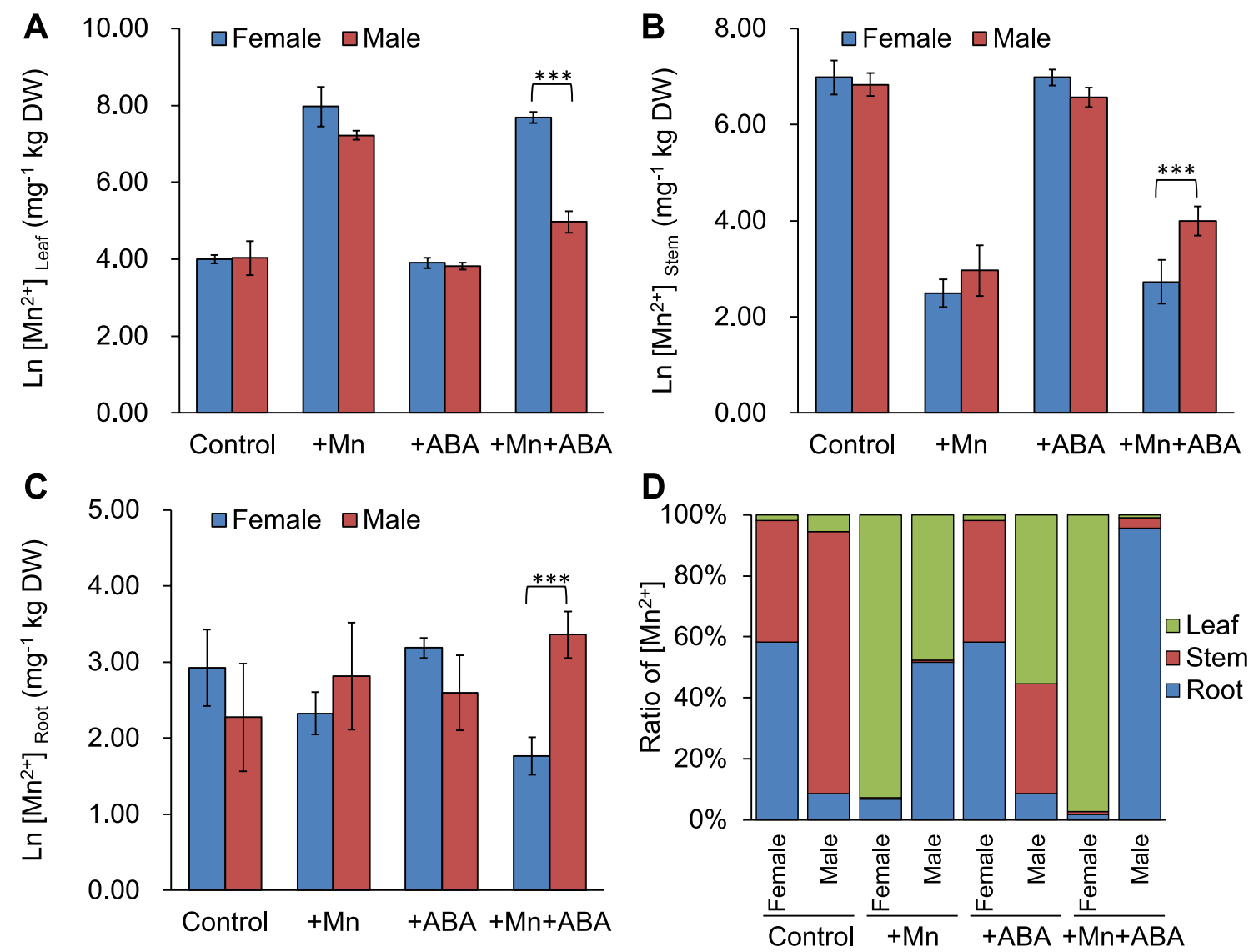

Fig. $1 \mathrm{Mn}^{2+}$ concentration in a leaves, b stems and c roots, and proportions of $\mathrm{Mn}^{2+}$ in those three parts in $P$. cathayana females and males (d). Data represent the mean $\pm \mathrm{SE}(n=3)$. Asterisks indicate a significant difference $(P<0.01)$ between females and males

\section{PCA analysis of Mn concentrations in females and males}

To determine whether females and males respond similarly to high $\mathrm{Mn}$ and $\mathrm{ABA}$ treatments, we compared the responses to Mn using the principal component analysis (PCA). The first PCA axis (PCA1) was identified as an axis of Mn concentrations, accounting for $61 \%$ of the total variance. PCA1 clearly separated control and Mn-treated females (Fig. 2), while in males, the separation by PCA1 was not clear, especially between the ABA-sprayed individuals with or without Mn treatment (Fig. 2). The results indicated that under ABA spraying, the Mn location pattern of Mn-treated males returned to that of control males. However, ABA spraying did not influence much the Mn location pattern of Mn-treated females. The Mn concentration in female leaves stayed high even when sprayed with $\mathrm{ABA}$, but in males, the Mn concentration of leaves was reduced by ABA spraying (Fig. 2).

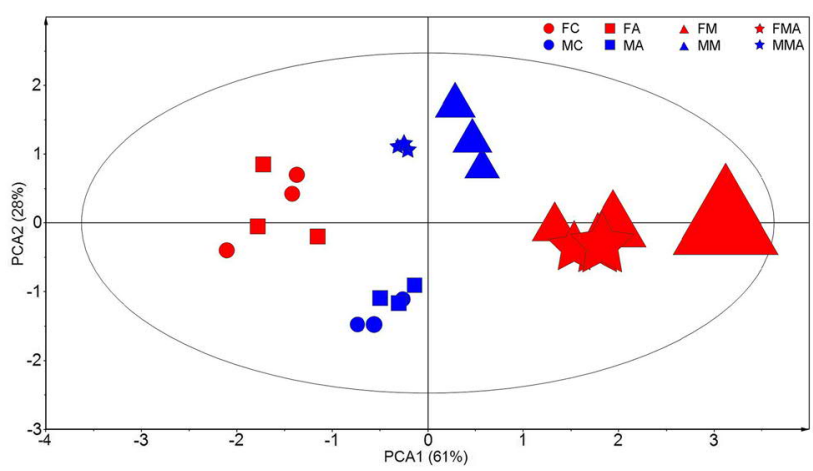

Fig. 2 PCA plots of Mn concentration in P. cathayana females and males in control, high Mn stress, $\mathrm{ABA}$ spraying and $\mathrm{ABA} \times \mathrm{Mn}$ combination conditions. $M C$ control male, $M A$ ABA-treated male, $M M$ manganese-treated male, $M M A$ manganese- and ABA-treated male, $F C$ control female, $F A$ ABA-treated female, $F M$ manganese-treated female, FMA manganese- and ABA-treated female. Symbol sizes indicate the Mn concentration in leaves 


\section{Sexual differences in ultrastructural damage}

To examine the effect of ABA on Mn-induced cell damage, the cellular ultrastructure was investigated. Mn toxicity caused more grievous vacuolation in female mesophyll chloroplasts than in male poplars while ABA alone treatment did not influence both females and males much (Fig. 3b, c, f, g). However, ABA spraying offset the Mn-induced vacuolation (Fig. 3d, h). In addition, when facing with the combination of high $\mathrm{Mn}$ and $\mathrm{ABA}$, grana were fewer in females than in males (Fig. 3d, h). The results indicated that high Mn stress causes damage to the mesophyll cell structure in both sexes, while ABA protects male mesophyll cells more than those in females.

\section{Discussion}

Although many studies have investigated sex-related tolerances to abiotic stresses (Barrett and Hough 2012; Case and Barrett 2004; Groen et al. 2010; Rozas et al. 2009; Wang and Curtis 2001), little is known about the function of ABA on stress mitigation in dioecious plants. In the present study, we analyzed photosynthesis, Mn reallocation and ultrastructure changes in $P$. cathayana females and males under a single treatment with high $\mathrm{Mn}$ or ABA spraying, and under the combined treatment of high $\mathrm{Mn}$ or ABA spraying. Our results showed that an exogenous application of ABA induced sexually different responses in Mn reallocation to roots, stems and leaves that could induce different degrees of damage on the subcellular structure and photosynthesis capacity in males and females. The data presented here offered insight into the effects of ABA on dioecy plants.

\section{ABA contributes to higher photosynthesis capacity in males when facing high Mn}

ABA is known to improve photosynthetic capacity when plants face abiotic stresses (Ashraf and Harris 2013; Zhang et al. 2008). ABA was believed to cause stomatal closure in some plants, and induce a decrease in $E$ afterwards (Cutler et al. 2010). It is also proposed that ABA plays a redox-retrograde role in the $A P X 2$ expression signaling network, which is harmful to the photosynthetic apparatus (Galvez-Valdivieso et al. 2009), while ABA might improve the PSII thermo-tolerance (Hao et al. 2012). Our results show that high Mn stress led to a decrease in the photosynthetic capacity of both male and female $P$. cathayana, while ABA prevented such decreases. Intriguingly, the photosynthetic capacity of Mn-treated males was a little higher than that of Mn-treated females when sprayed with ABA (Tables 1,2), which might result from the fact that males protect their photosynthetic apparatus better via ABA-induced blocking of Mn transportation from roots to aerial parts (Dučić et al. 2006; Shao et al. 2017) (Figs. 1, 3).

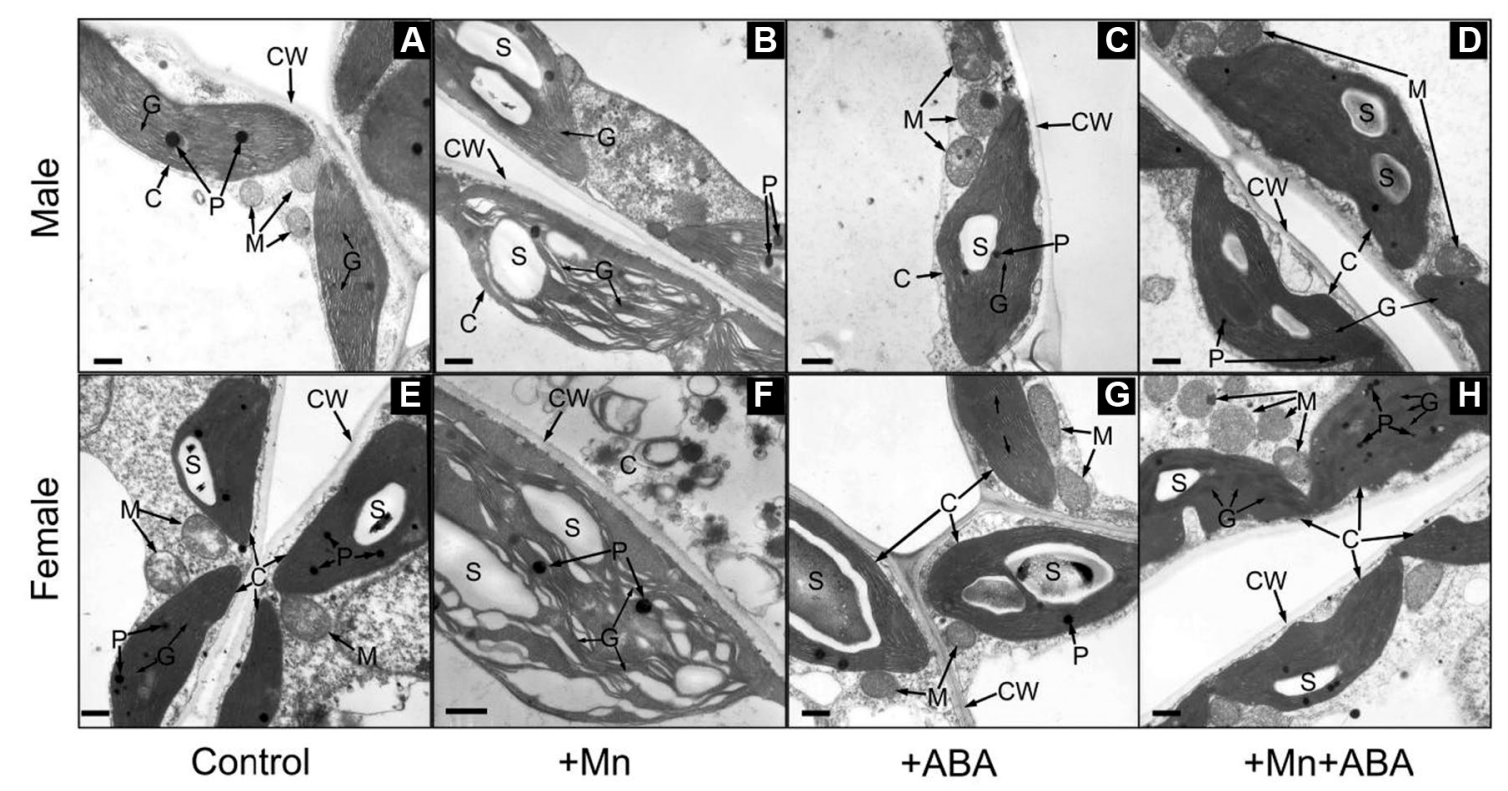

Fig. 3 Transmission electron microscopy observations of mesophyll cells in $P$. cathayana males (a-d) and females (e-h) under control conditions (a, e), and as affected by Mn stress alone $(\mathbf{b}, \mathbf{f})$, ABA alone

(c, g) and the combined treatment $(\mathbf{d}, \mathbf{h})$. The bars shown are $1 \mu \mathrm{m}$. $C$ chloroplast, $C W$ cell wall, $G$ granum, $M$ mitochondrion, $P$ plastoglobuli, $S$ starch granule 


\section{ABA inhibits Mn transportation from roots to aerial parts more in males}

Plants have evolved various transportation networks to reduce the damage caused by excessive levels of ions (Horie et al. 2009; Krämer et al. 2007; Millaleo et al. 2010; Ryan et al. 1997). ABA-inducible gene expression can be immediately triggered by abiotic stress and subsequently followed by stomatal closure that could further lead to lower transpiration (Peleg and Blumwald 2011). As a result of lower transpiration, the Mn transportation from roots to aerial parts decreases (Millaleo et al. 2010; Scoffoni et al. 2015). Our results showed that $\mathrm{ABA}$ spraying induced $\mathrm{Mn}$ reallocation to take place mainly in female leaves and in male roots (Figs. 1, 2). This result indicates that with the help of ABA, males could inhibit more $\mathrm{Mn}$ transport from roots to aerial parts, consequently causing less $\mathrm{Mn}$ accumulation in aerial parts, especially in leaves, when compared to females. As a result, the leaf photosynthetic apparatus of males could be protected better than that of females when grown under excess Mn.

\section{Male chloroplasts are less damaged by excess Mn when sprayed with ABA}

Excess metal ions are harmful to plant cells, especially to the photosynthetic apparatus (Potters et al. 2007). Mn treatments have been identified to disrupt the thylakoid system arrangement, to induce chloroplast swelling, to increase the amounts of plastoglobuli, and to reduce starch accumulation in chloroplasts (Najeeb et al. 2009). Similarly, P. cathayana showed severe loose thylakoid membranes and swollen chloroplasts under high Mn stress (Fig. 3b, f). However, female mesophyll cells were injured more severely compared to male cells. The same situation has been observed in previous studies on poplars exposed to excess salt, drought and heavy metals (Chen et al. 2011, 2013b; Zhang et al. 2010). Intriguingly, toxic symptoms caused by excess Mn were alleviated by ABA (Fig. 3d, h). Combined with the lower Mn abundance in male leaves, we concluded that males could protect chloroplast from excess Mn toxicity better than females through ABA-mediated inhibition of Mn transportation from roots to aerial parts.

\section{Conclusions}

Our results demonstrated that the Mn transportation from roots to aerial parts was blocked off by exogenous ABA more in $P$. cathayana males than females. As a result, especially the photosynthesis apparatus of males was less damaged by $\mathrm{Mn}$ than that of females. Consequently, the photosynthesis capacity of males suffered little when faced with high Mn. In summary, Mn stress resistance could be enhanced by exogenous ABA more in males than in females. Further studies should focus deeper on the question why ABA provides better resistance to $\mathrm{Mn}$ in males than in females.

Author contribution statement FC developed the initial research idea and designed the experiment. He also conducted the field work and was responsible for the statistical analysis and manuscript writing. JS, DM, LK, XT and HK contributed largely to the writing of the manuscript and provided useful suggestions and comments. CL acquired the funding for the project that was performed in his laboratory. $\mathrm{He}$ also contributed to the writing of the paper.

Acknowledgements This work was supported by the National Natural Science Foundation of China (31200469), the Anhui Provincial Natural Science Foundation (1308085QC62) and the Talent Program of the Hangzhou Normal University (2016QDL020).

\section{Compliance with ethical standards}

Conflict of interest The authors declare that they have no conflicts of interest.

\section{References}

Ashraf M, Harris P (2013) Photosynthesis under stressful environments: an overview. Photosynthetica 51:163-190

Baker NR (2008) Chlorophyll fluorescence: a probe of photosynthesis in vivo. Annu Rev Plant Biol 59:89-113

Barrett SCH, Hough J (2012) Sexual dimorphism in flowering plants. J Exp Bot 64:67-82

Case A, Barrett S (2004) Environmental stress and the evolution of dioecy: Wurmbea dioica (Colchicaceae) in Western Australia. Evol Ecol 18:145-164

Chen F, Chen L, Zhao H, Korpelainen H, Li C (2010) Sex-specific responses and tolerances of Populus cathayana to salinity. Physiol Plant 140:163-173

Chen F, Zhang S, Jiang H, Ma W, Korpelainen H, Li C (2011) Comparative proteomics analysis of salt response reveals sex-related photosynthetic inhibition by salinity in Populus cathayana cuttings. J Proteome Res 10:3944-3958

Chen F, Zhang S, Zhu G, Korpelainen H, Li C (2013a) Populus cathayana males are less affected than females by excess manganese: comparative proteomic and physiological analyses. Proteomics 13:2424-2437

Chen L, Wang L, Chen F, Korpelainen H, Li C (2013b) The effects of exogenous putrescine on sex-specific responses of Populus cathayana to copper stress. Ecotox Environ Safe 97:94-102

Chen Z, Fujii Y, Yamaji N, Masuda S, Takemoto Y, Kamiya T, Yusuyin Y, Iwasaki K, Kato S-i, Maeshima M, Ma JF, Ueno D (2013c) Mn tolerance in rice is mediated by MTP8.1, a member of the cation diffusion facilitator family. J Exp Bot 64:4375-4387

Chen J, Dong T, Duan B, Korpelainen H, Niinemets Ü, Li C (2015) Sexual competition and N supply interactively affect the dimorphism and competiveness of opposite sexes in Populus cathayana. Plant Cell Environ 38:1285-1298

Crossgrove J, Zheng W (2004) Manganese toxicity upon overexposure. NMR Biomed 17:544-553 
Cutler SR, Rodriguez PL, Finkelstein RR, Abrams SR (2010) Abscisic acid: emergence of a core sgnaling network. Annu Rev Plant Biol 61:651-679

De Vleesschauwer D, Yang Y, Vera Cruz C, Höfte M (2010) Abscisic acid-induced resistance against the brown spot pathogen Cochliobolus miyabeanus in rice involves MAP kinase-mediated repression of ethylene signaling. Plant Physiol 152:2036-2052

Doncheva S, Georgieva K, Vassileva V, Stoyanova Z, Popov N, Ignatov $\mathrm{G}$ (2005) Effects of succinate on manganese toxicity in pea plants. J Plant Nutr 28:47-62

Dorling SJ, Leung S, Anderson CWN, Albert NW, McManus MT (2011) Changes in 1-aminocyclopropane-1-carboxlate (ACC) oxidase expression and enzyme activity in response to excess manganese in white clover (Trifolium repens L.). Plant Physiol Biochem 49:1013-1019

Dučić T, Leinemann L, Finkeldey R, Polle A (2006) Uptake and translocation of manganese in seedlings of two varieties of Douglas fir (Pseudotsuga menziesii var. viridis and glauca). New Phytol 170:11-20

Fan SK, Fang XZ, Guan MY, Ye YQ, Lin XY, Du ST, Jin CW (2014) Exogenous abscisic acid application decreases cadmium accumulation in Arabidopsis plants, which is associated with the inhibition of IRT1-mediated cadmium uptake. Front Plant Sci 5:1-8

Fernando DR, Woodrow IE, Jaffré T, Dumontet V, Marshall AT, Baker AJM (2008) Foliar manganese accumulation by Maytenus founieri (Celastraceae) in its native New Caledonian habitats: populational variation and localization by X-ray microanalysis. New Phytol 177:178-185

Foy C, Chaney R, White M (1978) The physiology of metal toxicity in plants. Annu Rev Plant Biol 29:511-566

Freeman DC, Klikoff LG, Harper KT (1976) Differential resource utilization by the sexes of dioecious plants. Science 193:597-599

Galvez-Valdivieso G, Fryer MJ, Lawson T, Slattery K, Truman W, Smirnoff N, Asami T, Davies WJ, Jones AM, Baker NR, Mullineaux PM (2009) The high light response in Arabidopsis involves ABA signaling between vascular and bundle sheath cells. Plant Cell 21:2143-2162

Groen K, Stieha C, Crowley P, McLetchie D (2010) Sex-specific plant responses to light intensity and canopy openness: implications for spatial segregation of the sexes. Oecologia 162:561-570

Hao HP, Jiang CD, Zhang SR, Tang YD, Shi L (2012) Enhanced thermal-tolerance of photosystem II by elevating root zone temperature in Prunus mira Koehne seedlings. Plant Soil 353:367-378

Horie T, Hauser F, Schroeder JI (2009) HKT transporter-mediated salinity resistance mechanisms in Arabidopsis and monocot crop plants. Trends Plant Sci 14:660-668

Hsu YT, Kao CH (2003) Role of abscisic acid in cadmium tolerance of rice (Oryza sativa L.) seedlings. Plant Cell Environ 26:867-874

Hultine KR, Burtch KG, Ehleringer JR (2013) Gender specific patterns of carbon uptake and water use in a dominant riparian tree species exposed to a warming climate. Global Change Biol 19:3390-3405

Krämer U, Talke IN, Hanikenne M (2007) Transition metal transport. FEBS Lett 581:2263-2272

Lee S, Lee E, Yang E, Lee J, Park A, Song W, Park O (2004) Proteomic identification of annexins, calcium-dependent membrane binding proteins that mediate osmotic stress and abscisic acid signal transduction in Arabidopsis. Plant Cell 16:1378-1391

Lei Y, Korpelainen H, Li C (2007) Physiological and biochemical responses to high Mn concentrations in two contrasting Populus cathayana populations. Chemosphere 68:686-694

Lidon FC, Barreiro MG, Ramalho JC (2004) Manganese accumulation in rice: implications for photosynthetic functioning. J Plant Physiol 161:1235-1244

Millaleo R, Reyes-Diaz M, Ivanov AG, Mora ML, Alberdi M (2010) Manganese as essential and toxic element for plants: transport, accumulation and resistance mechanisms. J Soil Sci Plant Nutr 10:476-494

Najeeb U, Xu L, Ali S, Jilani G, Gong HJ, Shen WQ, Zhou WJ (2009) Citric acid enhances the phytoextraction of manganese and plant growth by alleviating the ultrastructural damages in Juncus effusus L. J Hazard Mater 170:1156-1163

Obeso JR (2002) The costs of reproduction in plants. New Phytol 155:321-348

Peleg Z, Blumwald E (2011) Hormone balance and abiotic stress tolerance in crop plants. Curr Opin Plant Biol 14:290-295

Pieterse CMJ, Van der Does D, Zamioudis C, Leon-Reyes A, Van Wees SCM (2012) Hormonal modulation of plant immunity. Annu Rev Cell Dev Biol 28:489-521

Pittman JK (2005) Managing the manganese: molecular mechanisms of manganese transport and homeostasis. New Phytol 167:733-742

Potters G, Pasternak TP, Guisez Y, Palme KJ, Jansen MA (2007) Stress-induced morphogenic responses: growing out of trouble? Trends Plant Sci 12:98-105

Raghavendra AS, Gonugunta VK, Christmann A, Grill E (2010) ABA perception and signalling. Trends Plant Sci 15:395-401

Reis ARD, Junior JL (2011) Genotypic influence on the absorption, use and toxicity of manganese by soybean. In: Sudaric A (ed) Soybean-molecular aspects of breeding, vol 11. InTech, Rijeka, pp 241-258

Rezai K, Farboodnia T (2008) The response of pea plant (Pisum sativum) to manganese toxicity in solution culture. Agric J 3:248-251

Rozas V, DeSoto L, Olano JM (2009) Sex-specific, age-dependent sensitivity of tree-ring growth to climate in the dioecious tree Juniperus thurifera. New Phytol 182:687-697

Ryan P, Skerrett M, Findlay G, Delhaize E, Tyerman S (1997) Aluminum activates an anion channel in the apical cells of wheat roots. Proc Natl Acad Sci USA 94:6547

Ryu MY, Cho SK, Kim WT (2010) The Arabidopsis C3H2C3-type RING E3 ubiquitin ligase AtAIRP1 is a positive regulator of an abscisic acid-dependent response to drought stress. Plant Physiol 154:1983-1997

Scoffoni C, Kunkle J, Pasquet-Kok J, Vuong C, Patel AJ, Montgomery RA, Givnish TJ, Sack L (2015) Light-induced plasticity in leaf hydraulics, venation, anatomy, and gas exchange in ecologically diverse Hawaiian lobeliads. New Phytol 207:43-58

Shao JF, Yamaji N, Shen RF, Ma JF (2017) The key to Mn homeostasis in plants: regulation of Mn transporters. Trends Plant Sci 22:215-224

Shi WG, Li H, Liu TX, Polle A, Peng CH, Luo ZB (2015) Exogenous abscisic acid alleviates zinc uptake and accumulation in Populus $\mathrm{x}$ canescens exposed to excess zinc. Plant Cell Environ 38:207-223

Stark LR, Mishler BD, McLetchie DN (2000) The cost of realized sexual reproduction: assessing patterns of reproductive allocation and sporophyte abortion in a desert moss. Am J Bot 87:1599-1608

Wallace CS, Rundel PW (1979) Sexual dimorphism and resource allocation in male and female shrubs of Simmondsia chinensis. Oecologia 44:34-39

Wang X, Curtis PS (2001) Gender-specific responses of Populus tremuloides to atmospheric $\mathrm{CO}_{2}$ enrichment. New Phytol 150:675-684

Wang ZY, Xiong L, Li W, Zhu JK, Zhu J (2011) The plant cuticle is required for osmotic stress regulation of abscisic acid biosynthesis and osmotic stress tolerance in Arabidopsis. Plant Cell 23:1971-1984

Xu GY, Rocha PCF, Wang ML, Xu ML, Cui YC, Li LY, Zhu YX, Xia $\mathrm{X}$ (2011) A novel rice calmodulin-like gene, OsMSR2, enhances drought and salt tolerance and increases ABA sensitivity in Arabidopsis. Planta 234:47-59

Xue S, Chen Y, Reeves RD, Baker AJM, Lin Q, Fernando DR (2004) Manganese uptake and accumulation by the hyperaccumulator plant Phytolacca acinosa Roxb. (Phytolaccaceae). Environ Pollut 131:393-399 
Yin C, Duan B, Wang X, Li C (2004) Morphological and physiological responses of two contrasting poplar species to drought stress and exogenous abscisic acid application. Plant Sci 167:1091-1097

Zhang X, Wollenweber B, Jiang D, Liu F, Zhao J (2008) Water deficits and heat shock effects on photosynthesis of a transgenic Arabidopsis thaliana constitutively expressing $A B P 9$, a bZIP transcription factor. J Exp Bot 59:839-848
Zhang S, Chen F, Peng S, Ma W, Korpelainen H, Li C (2010) Comparative physiological, ultrastructural and proteomic analyses reveal sexual differences in the responses of Populus cathayana under drought stress. Proteomics 10:1-17 